\title{
Identification of adhesion-associated DNA methylation patterns in the peripheral nervous system
}

\author{
SHANHUAI ZUO ${ }^{1 *}$, GUIDONG SHI $^{2,3^{*}}$, JIANCHAO FAN $^{2,3 *}$, BAOYOU FAN ${ }^{2,3}$, XIAOLEI ZHANG ${ }^{2,3}$, \\ SHEN LIU ${ }^{2,3}$, YAN HAO ${ }^{2,3}$, ZHIJIAN WEI ${ }^{2,3}$, XIANHU ZHOU ${ }^{2,3}$ and SHIQING FENG ${ }^{2,3}$ \\ Departments of ${ }^{1}$ Radiology and ${ }^{2}$ Orthopedics, Tianjin Medical University General Hospital; \\ ${ }^{3}$ International Science and Technology Cooperation Base of Spinal Cord Injury, \\ Tianjin Key Laboratory of Spine and Spinal Cord Injury, Department of Orthopedics, \\ Tianjin Medical University General Hospital, Heping, Tianjin 300052, P.R. China
}

Received April 24, 2020; Accepted August 26, 2020

DOI: 10.3892/etm.2020.9479

\begin{abstract}
Schwann cells are unique glial cells in the peripheral nervous system. These cells provide a range of cytokines and nutritional factors to maintain axons and support axonal regeneration. However, little is known concerning adhesion-associated epigenetic changes that occur in Schwann cells after peripheral nerve injury (PNI). In the present study, adhesion-associated DNA methylation biomarkers were assessed between normal and injury peripheral nerve. Specifically, normal Schwann cells (NSCs) and activated Schwann cells (ASCs) were obtained from adult Wistar rats. After the Schwann cells were identified, proliferation and adhesion assays were used to assess differences between NSCs and ASCs. Methylated DNA immunoprecipitation-sequencing and bioinformatics analysis were used to identify and analyze the differentially methylated genes. Reverse transcription-quantitative PCR was performed to assess the expression levels of adhesion-associated genes. In the present study, the proliferation and adhesion assays demonstrated that ASCs had a more robust proliferative activity and adhesion compared with NSCs. Gene Ontology and Kyoto Encyclopedia of Genes and Genomes enrichment analyses were performed to identify methylation-associated biological processes and signaling pathways. Protein-protein interaction network analysis revealed that Fyn, Efna1, Jak2, Vav3, Flt4, Epha7, Crk, Kitlg,
\end{abstract}

Correspondence to: Professor Xianhu Zhou or Professor Shiqing Feng, Department of Orthopedics, Tianjin Medical University General Hospital, 154 Anshan Road, Heping, Tianjin 300052, P.R. China

E-mail: zhouxh007@126.com

E-mail: sqfeng@tmu.edu.cn

${ }^{*}$ Contributed equally

Key words: DNA methylation, Schwann cells, cell adhesion, peripheral nerve injuries, bioinformatics, Gene Ontology, Kyoto Encyclopedia of Genes and Genomes, nerve regeneration, protein-protein interaction network
Ctnnb1 and Ptpn11 were potential markers for Schwann cell adhesion. The expression levels of several adhesion-associated genes, such as vinculin, BCAR1 scaffold protein, collagen type XVIII $\alpha 1$ chain and integrin subunit $\beta 6$, in ASCs were altered compared with those in NSCs. The current study analyzed adhesion-associated DNA methylation patterns of Schwann cells and identified candidate genes that may potentially regulate Schwann cell adhesion in Wistar rats before and after PNI.

\section{Introduction}

Peripheral nerve injury (PNI) poses a significant challenge in the medical field worldwide, resulting in issues such as the economic loss of the patient's family and society, physical disability and mental shock (1-4). Symptoms caused by various open and closed peripheral nerve injuries include neuropathic palsy, motor dysfunction, muscle atrophy and neuropathic pain (5-8). Pain reduction in patients with PNI is an important area of focus in medicine. Previous studies have demonstrated that Schwann cells serve an important role in promoting axonal regeneration, myelin repair and functional recovery in neuroregeneration (9-11).

Schwann cells have been the focus of research on neural regeneration due to their ability to promote axon regeneration (12-16). After PNI, Schwann cells turn into an 'activated state' and acquire the capacity to migrate, proliferate and secrete soluble mediators that control Wallerian degeneration and axonal regeneration (17-20). Previous studies have demonstrated that activated Schwann cells (ASCs) can be extracted from pre-injured peripheral nerves $(21,22)$. In brief, the sciatic nerve was exposed through a dorsal the incision under general anesthesia and ligated to allow pre-degeneration to take place. One week later, the distal segment of the pre-degenerated sciatic nerve was removed in order to isolate activated Schwann cells. Furthermore, current research has focused on combining ASCs with various biomaterials to repair nerve damage (23). In 2012, Zhou et al (24) used human autologous activated Schwann cells to repair spinal cord injury and achieved notable results. Besides, ASCs also be combined with some scaffold as one of the promising methods to treat spinal cord injury (25). A previous study revealed that the survival of Schwann cells 
was enhanced by exposure to perfluorotributylamine through the promotion of sciatic nerve regeneration (26).

DNA methylation, which directs transcriptional silencing via heterochromatin formation, is a genetic marker for the growth and development of a number of eukaryotes (27-29). As one of the earliest epigenetic modifications to be recognized, DNA methylation has been observed in numerous organisms (30,31). Methylation of eukaryotic DNA typically occurs at position 5 of cytosine to produce 5-methylcytosine (32). A previous study reported that PNI led to DNA methylome remodeling in rat dorsal root ganglion (33). These observations suggest that the biological impact of DNA methylation should not be underestimated. In our previous studies, a genome-wide methylation analysis and isobaric tags for relative and absolute quantitation (iTRAQ)-based proteomics profiling were performed to compare normal Schwann cells (NSCs) and ASCs $(34,35)$. However, to the best of our knowledge, no studies have compared the functional changes associated with adhesion and proliferation between NSCs and ASCs.

In the present study, both NSCs and ASCs were isolated from the sciatic nerve of Wistar rats and purified using differential adhesion methods. Subsequently, several assays were performed, including proliferation and adhesion assays, reverse transcription-quantitative (RT-q)PCR, bioinformatic analysis and methylated DNA immunoprecipitation-sequencing (MeDIP-seq) analysis.

\section{Materials and methods}

Ethics. All animal handling experimental protocols and procedures were approved by the Animal Care and Use Committee of Tianjin Medical University General Hospital (Tianjin, China). Wistar rats $(100 \pm 10 \mathrm{~g})$ were provided by the Laboratory Animal Center of the Chinese People's Liberation Army General Hospital (Beijing, China; Animal license no. SCXK2012-0066).

Preparation of Schwann cells. Schwann cells were isolated from the proximal section of the sciatic nerves of Wistar rats, as previously described $(36,37)$. All cells were cultured with a culture medium contain Dulbecco's modified Eagle's medium (DMEM; Gibco; Thermo Fisher Scientific, Inc.) with $10 \%$ fetal bovine serum (FBS; Gibco; Thermo Fisher Scientific, Inc.) and $1 \%$ Antibiotic-Antimycotic (AA) in $5 \% \mathrm{CO}_{2}$ at $37^{\circ} \mathrm{C}$. A total of 18 Wistar female rats (4 weeks, $100 \pm 10 \mathrm{~g}$ ) were acclimatized for $\geq 2$ weeks under a humidity- and temperature-controlled environment with a 12-h light/dark cycle before surgery. All rats had free access to food and water, and the health and behavior of rats were monitored once per day. Before surgery, all rats were deeply anesthetized using $2 \%$ isoflurane to minimize suffering. Subsequently, each rat received unilateral ligation of the sciatic nerve. One week after surgery, all rats were euthanized using $5 \%$ isoflurane until respiration ceased and death ensued. There were two groups in the present study: Group A, ASCs from the ligated sciatic nerves of all rats $(n=18)$; and Group B, NSCs from the untreated sciatic nerves of all rats $(n=18)$.

The euthanasia protocols and procedures of Tianjin Medical University General Hospital are based on and consistent with the Institutional Animal Care and Use Committee of the University of Iowa (38). Additionally, 5\% isoflurane was used for sacrifice of the rats as previously described (39-41). No other physical method was used as the second sacrifice method. Two different methods were used in the present study to confirm death: i) Heartbeat, heartbeat was assessed for 10 min after euthanasia, and a lack of electrical activity of the heart as determined by electrocardiogram; ii) respiratory pattern, the respiratory pattern was assessed for $10 \mathrm{~min}$ after euthanasia, and a lack of breathing for $>10 \mathrm{~min}$.

Characterization of Schwann cells. For immunofluorescence labeling, Schwann cells from the different groups were fixed in $4 \%$ paraformaldehyde $\left(\right.$ ChemCruz $^{\mathrm{TM}}$ Biochemicals; Santa Cruz Biotechnology, Inc.) at room temperature for $15 \mathrm{~min}$. Subsequently, the cells were permeabilized with $0.1 \%$ Triton X-100 (Sigma-Aldrich; Merck KGaA) at room temperature for $10 \mathrm{~min}$ and incubated with $5 \%$ normal goat serum (Cell Signaling Technology, Inc.) at room temperature for 1 h. A primary rabbit anti-rat S100 (1:200; cat. no. ab52642; Abcam) antibody was added to the cells and incubated at $37^{\circ} \mathrm{C}$ for $2 \mathrm{~h}$. Fluorescein isothiocyanate-conjugated goat anti-rabbit IgG (1:500; cat. no. 111-545-003; Jackson ImmunoResearch Laboratories, Inc.) was added as a secondary antibody. The nucleus was stained with DAPI (Sigma-Aldrich; Merck KGaA) at room temperature for $10 \mathrm{~min}$. Finally, cells were observed under an inverted fluorescence microscope (magnification, x20; Leica Microsystems $\mathrm{GmbH}$ ). All images were imported into Zeiss confocal system (v3.0) for further analysis and statistics.

Proliferation and adhesion assays. A WST-8 assay was used for the second passages cells in order to investigate the cell proliferation according to previous publications (42-44). Briefly, Schwann cells were seeded into 96-well plates at a density of $1 \times 10^{3}$ cells/well, the Cell Counting Kit-8 (Dojindo Molecular Technologies, Inc.) solution was added to the culture medium, and cells were incubated at $37^{\circ} \mathrm{C}$ for $1.5 \mathrm{~h}$. The absorbance was measured at $450 \mathrm{~nm}$.

For cell adhesion assays, Schwann cells were seeded into six-well plates (cat. no. SRP3186; Sigma-Aldrich; Merck $\mathrm{KGaA}$ ) coated with vitronectin at a density of $3 \times 10^{5}$ cells/well. After 45 min of incubation at $37^{\circ} \mathrm{C}$, cells were washed five times with PBS (Gibco; Thermo Fisher Scientific, Inc.) and fixed in $4 \%$ paraformaldehyde at room temperature for $15 \mathrm{~min}$. Adherent cells were stained with crystal violet $\left(1 \%\right.$ in $\mathrm{ddH}_{2} \mathrm{O}$; Sigma-Aldrich; Merck KGaA) at room temperature for $10 \mathrm{~min}$. Six fields of view/well (magnification, x200) were randomly selected and the number of cells adherent to the bottom of plates was counted manually with a counting chamber (Hausser Scientific Co.) under the light scope (Zeiss AG) $(45,46)$.

$R T$ - $q P C R$. Total RNA was extracted from Schwann cells using trizol reagent (Beijing Solarbio Science \& Technology Co., Ltd.). Total RNA (1 $\mu \mathrm{g} /$ sample) was reverse transcribed $\left(5 \mathrm{~min}\right.$ at $20^{\circ} \mathrm{C}, 20 \mathrm{~min}$ at $46^{\circ} \mathrm{C}, 1 \mathrm{~min}$ at $95^{\circ} \mathrm{C}$ and held at $4^{\circ} \mathrm{C}$ ) using a Reverse Transcription kit (Takara Bio, Inc.). qPCR was performed with the SYBR Green PCR Master Mix (Applied Biosystems; Thermo Fisher Scientific, Inc.) on a CFX96 Touch $^{\mathrm{TM}}$ Deep Well Real-Time PCR Detection system (Bio-Rad Laboratories, Inc.) according to previous publications $(47,48)$. Briefly, the thermal program consisted of 
Table I. Details of the primers used for quantitative PCR.

\begin{tabular}{|c|c|c|c|c|c|}
\hline Gene & $\begin{array}{l}\text { NCBI } \\
\text { accession no. }\end{array}$ & $\begin{array}{l}\text { Product } \\
\text { length }\end{array}$ & Forward primer, 5'-3' & Reverse primer, 5'-3' & $\begin{array}{c}\text { Annealing } \\
\text { temperature, }{ }^{\circ} \mathrm{C}\end{array}$ \\
\hline$\beta$-actin & NM_031144.3 & 85 & AGCGTGGCTACAGCTTCACC & $\begin{array}{l}\text { AAGTCTAGGGCAAC } \\
\text { ATAGCACAGC }\end{array}$ & 57.5 \\
\hline$E z r$ & NM_019357.1 & 190 & $\begin{array}{l}\text { TGGACGACCGTAACGAGGA } \\
\text { GAAG }\end{array}$ & $\begin{array}{l}\text { CTGATCTGCCGCAGCGT } \\
\text { CTTATAC }\end{array}$ & 58.6 \\
\hline Itgb6 & XM_017591686.1 & 132 & $\begin{array}{l}\text { GCTCATCGGTGTCGTGCTA } \\
\text { CTG }\end{array}$ & $\begin{array}{l}\text { CCTCGGTACAGCGGATTG } \\
\text { GTTC }\end{array}$ & 58.2 \\
\hline Lamcl & NM_053966.2 & 173 & $\begin{array}{l}\text { AACGAGGTGAATGGCAT } \\
\text { GTTGAGG }\end{array}$ & $\begin{array}{l}\text { TGGCTGAGGAGGCTGCT } \\
\text { GAC }\end{array}$ & 58.6 \\
\hline Col3al & NM_032085.1 & 177 & $\begin{array}{l}\text { GACACGCTGGTGCTCAAG } \\
\text { GAC }\end{array}$ & $\begin{array}{l}\text { GTTCGCCTGAAGGACCTCG } \\
\text { TTG }\end{array}$ & 58.6 \\
\hline$V c l$ & XM_006251639.3 & 162 & $\begin{array}{l}\text { AAGGCAAGATTGAGCAGG } \\
\text { CACAG }\end{array}$ & $\begin{array}{l}\text { CACGGTCACACTTGGCGA } \\
\text { GAAG }\end{array}$ & 58.8 \\
\hline Col5a3 & XM_017595884.1 & 86 & $\begin{array}{l}\text { TCAGGTGACCACAGGC } \\
\text { ACTCTATC }\end{array}$ & $\begin{array}{l}\text { TTGATGGTGGCTGCTGTTG } \\
\text { TCTG }\end{array}$ & 58.7 \\
\hline Stat $5 a$ & NM_017064.1 & 102 & $\begin{array}{l}\text { GACCATCATCAGCGAGCA } \\
\text { GCAG }\end{array}$ & $\begin{array}{l}\text { TACTCCATGACGCAGCAGT } \\
\text { TGTTC }\end{array}$ & 58.3 \\
\hline Collsal & NM_053489.2 & 153 & $\begin{array}{l}\text { GAGTCAACAGTTCCTAC } \\
\text { GCACCAG }\end{array}$ & TGCCTGCATCGCCAACACTG & 58.3 \\
\hline Bcarl & XM_006255629.3 & 82 & AGCACACGCAGCAGCCAATC & $\begin{array}{l}\text { CCACAGCAACTTCCAGCTC } \\
\text { CAG }\end{array}$ & 58.6 \\
\hline
\end{tabular}

Vcl, vinculin; Bcar1, BCAR1 scaffold protein; Lamc1, laminin subunit $\gamma 1$; Col5a3, collagen type V $\alpha 3$ chain; Coll8al, collagen type XVIII $\alpha 1$ chain; Ezr, ezrin; Itgb6, integrin subunit $\beta 6$; Col3al, collagen type III $\alpha 1$ chain; NCBI, National Center for Biotechnology Information.

2 min at $95^{\circ} \mathrm{C}$, then 40 cycles of amplifications, $5 \mathrm{sec}$ at $95^{\circ} \mathrm{C}$ for denaturation, $5 \mathrm{sec}$ at $65^{\circ} \mathrm{C}$ for annealing, and $5 \mathrm{sec}$ at $95^{\circ} \mathrm{C}$ for extension. Each sample was analyzed in triplicate. The data were then calculated using the $2^{-\Delta \Delta \mathrm{Cq}}$ formula with reference to the basal controls. $\beta$-actin was used as an internal control. The expression levels of nine genes, namely vinculin ( $V c l)$, BCAR1 scaffold protein (Bcarl), laminin subunit $\gamma 1$ (Lamc1), collagen type V $\alpha 3$ chain (Col5a3), collagen type XVIII $\alpha 1$ chain (Coll8al), ezrin (Ezr), integrin subunit $\beta 6$ (Itgb6), collagen type III $\alpha 1$ chain (Col3al) and Stat5a, were evaluated in both NSCs and ASCs. Primer3 (v0.4.0) software was used for all PCR primer design. All primers are listed in Table I.

MeDIP-seq. MeDIP-seq was used to detect each sample according to the protocol of a previous study (Annoroad Genomics) (49). Briefly, $5 \mu \mathrm{g}$ DNA from each group (with two duplicates) was sonicated $(20 \mathrm{kHz})$ at $4^{\circ} \mathrm{C}$ for $10 \mathrm{~min}$ to produce DNA fragments (100-500 bp). Adapter-ligated DNA was immunoprecipitated at room temperature for $2 \mathrm{~h}$ using an anti-5-methylcytosine monoclonal antibody $(1: 1,000$; cat. no. ab214727; Abcam). Subsequently, RT-qPCR analysis was performed to verify the specificity of the immunoprecipitated fragments. A 200-300 bp DNA fragment was purified using a DNA Clean and Concentrator-5 column (D4003; Zymo Research Corp.). The amplicon quality and quantity were assessed using a 2100 analyzer DNA 1000 chip (Agilent Technologies, Inc.). MeDIP library was sequenced on an Illumina HiSeq 2000 Sequencing system (Illumina, Inc.).
Bioinformatics analysis. The adhesion-associated differential methylation regions (DMRs) between NSCs and ASCs were identified (mean difference, $\geq 20 ; \mathrm{P}<0.05$ ). All genes containing DMRs were used for Kyoto Encyclopedia of Genes and Genomes (KEGG) functional enrichment analysis and Gene Ontology (GO) analysis using the Database for Annotation, Visualization and Integrated Discovery (https://david.ncifcrf. gov/list.jsp) (50). The biological processes (BPs), cellular components (CCs) and molecular functions (MFs) of differentially expressed genes were evaluated in detail in GO analysis, while KEGG pathway analysis was used to investigate the systemic functional, chemical and genomic information of differentially methylated genes. $\mathrm{P}<0.001$ was used to denote the significance of GO and KEGG pathway enrichment in the differentially methylated genes (mean difference $\geq 20$, $\mathrm{P}<0.001)$.

Protein-protein interaction (PPI) network analysis. The information of the interaction of proteins, and neighborhood, gene fusions were provided using the Search Tool for the Retrieval of Interacting Genes (STRING) database (a publicly available database; http://string-db.org/) (51). In the present study, the input gene sets were gene modules and the species was Rattus norvegicus. To further explore the potential relevance of the differentially methylated genes in Schwann cells, an evidence threshold $>0.9$ was set as the cut-off value. The core genes were selected by the interaction with other genes and further verified by RTq-PCR. 

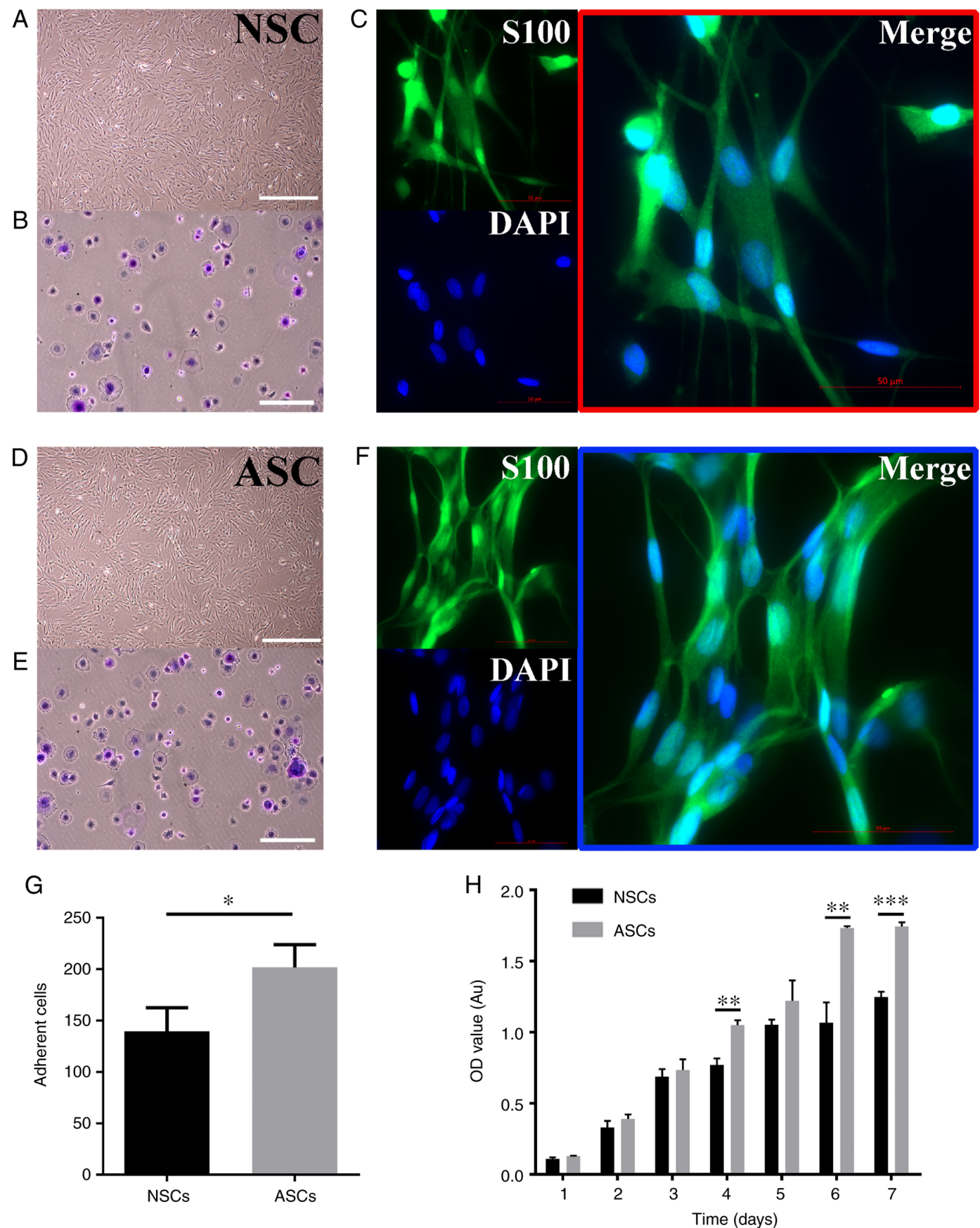

Figure 1. Culture and identification of Schwann cells. (A, D) The shape of NSCs and ASCs under an optical microscope, all cells were arranged in a long spindle shape and nucleus was oblong or ovoid. Scale bar: $200 \mu \mathrm{m}$ (B, E, G) Adhesion assay of Schwann cells. Scale bar: $100 \mu \mathrm{m}$. (C, F) Immunofluorescent staining images of s100, DAPI, and Merge of NSCs and ASCs. (H) Proliferation assay of ASCs and NSCs. ${ }^{*} \mathrm{P}<0.05 ;{ }^{* *} \mathrm{P}<0.01 ;{ }^{* * *} \mathrm{P}<0.001$. Scale bar, $50 \mu \mathrm{m}$. NSCs, normal schwann cells; ASCs, activated schwann cells; OD, optical density; Au, absorbance units.

Statistical analysis. GraphPad Prism statistical software (version 8.0.2; GraphPad Software, Inc.) was used to perform data analysis. Statistical differences between two groups were analyzed using paired Student's t-test. All data are presented as the mean \pm SEM. All experiments were repeated in triplicate. $\mathrm{P}<0.05$ was considered to indicate a statistically significant difference.

\section{Results}

ASCs exhibit a stronger proliferative capacity than NSCs. To investigate whether there were proliferation differences between ASCs and NSCs, a cell proliferation assay was performed. Both groups exhibited a sustained proliferation rate. ASCs exhibited a significantly higher proliferation activity after 4, 6 and 7 days compared with NSCs. However, no marked morphological differences were observed between the two groups when observed under an optical microscope (Fig. 1A). Furthermore, adhesion experiments were used to further verify whether adhesion of Schwann cells changed after PNI. The number of cells adherent to the bottom of the plates was counted. ASCs exhibited a significantly increased capacity of adhesion compared with NSCs (Fig. 1B). Additionally, both NSCs and ASCs were positive for S100 protein as revealed 
A

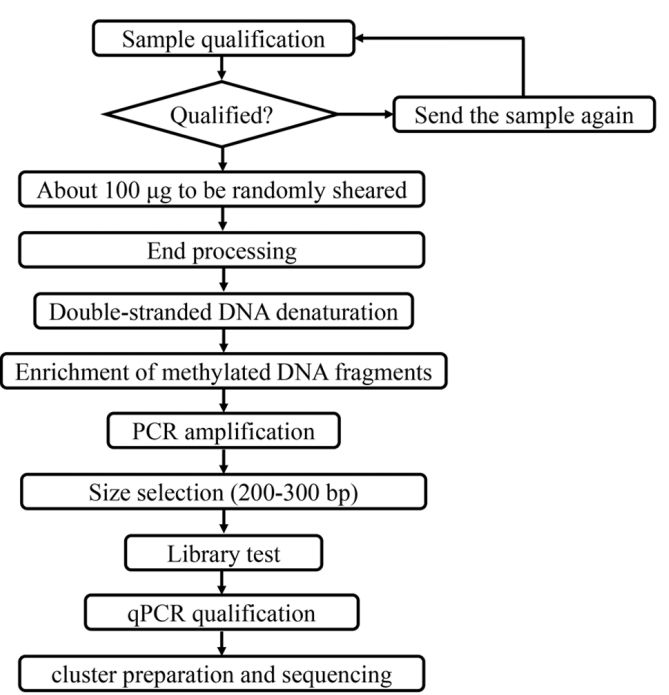

C

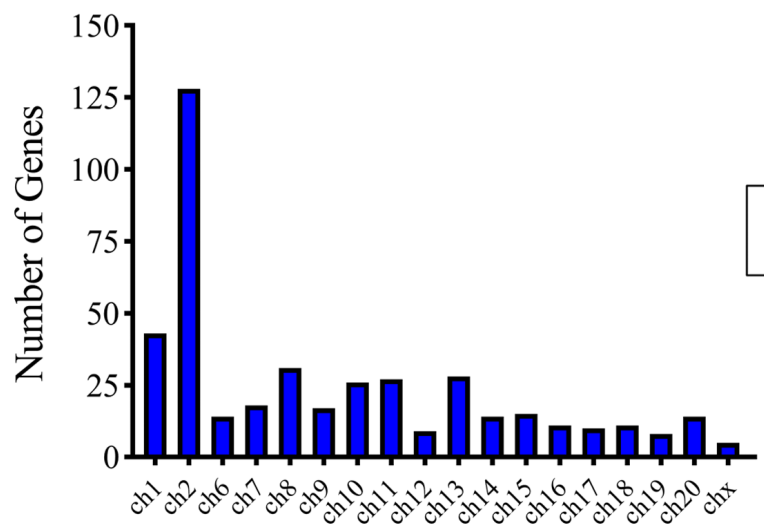

B

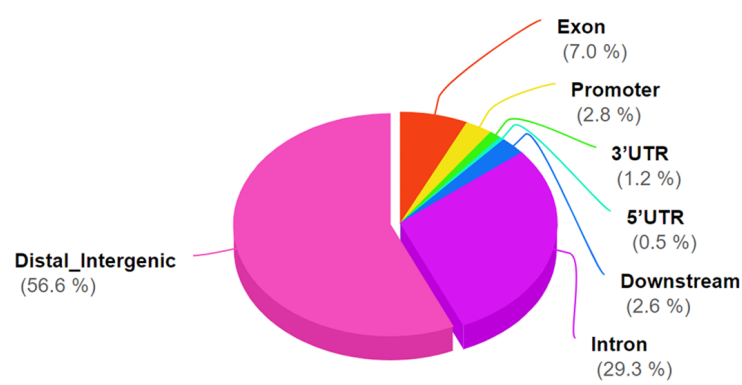

D

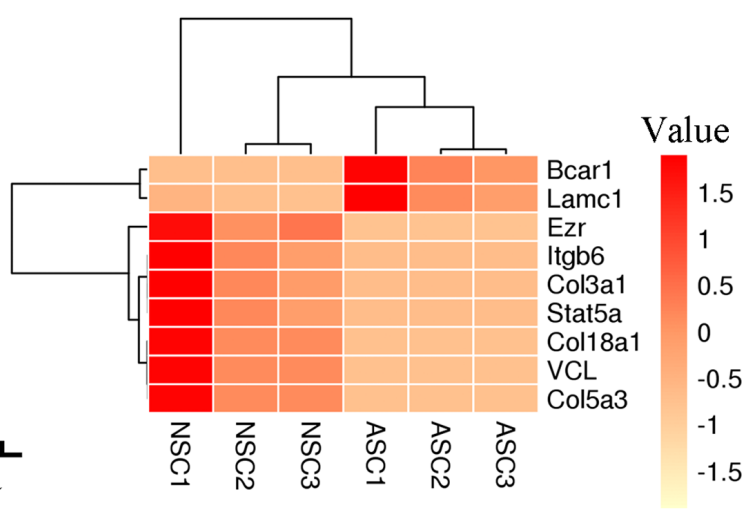

Figure 2. Expression signatures of differential methylation genes after PNI. (A) Concise experimental procedure for the Methylated DNA immunoprecipitationsequencing. (B) Differential methylation genes were classified according their genomic architecture after PNI. (C) Chromosome distribution showed the numbers of regulated genes located at different chromosomes. (D) Heat map of nine aberrantly expressed genes. Vcl, vinculin; Bcarl, BCAR1 scaffold protein; Lamcl, laminin subunit $\gamma 1$; Col5a3, collagen type V $\alpha 3$ chain; Coll8al, collagen type XVIII $\alpha 1$ chain; Ezr, ezrin; Itgb6, integrin subunit $\beta 6$; Col3al, collagen type III $\alpha 1$ chain; MeDIP-seq, methylated DNA immunoprecipitation-sequencing; PNI, peripheral nerve injury; ch, chromosome; NSC, normal Schwann cell; ASC, activated Schwann cell; qPCR, quantitative PCR.

by immunocytochemical staining under a fluorescence microscope (Fig. 1C).

Identification of adhesion-associated DMRs after PNI. Specific experimental procedures for MeDIP-seq are shown in Fig. 2A. A total of 429 differentially methylated genes associated with Schwann cell adhesion were identified. After PNI, DMRs were classified into seven major groups according to the genomic location, including distal intergenic (56.6\%), intron $(29.3 \%)$, exon $(7.0 \%)$, promoter $(2.8 \%), 3$ '-untranslated region (UTR; $1.2 \%)$, 5'-UTR $(0.5 \%)$ and downstream (2.6\%) (Fig. 2B). The chromosomal distribution of these DMRs after PNI is shown in Fig. 2C. In terms of chromosomal distribution, chromosome 2 had the greatest number of differentially methylated genes. Among all 429 differentially methylated genes, nine genes were selected according to the gene interaction with other genes, including: Vcl, Bcarl, Lamcl, Col5a3, Coll8a1, Ezr, Itgb6, Col3al and Stat5a. All of these nine aberrantly expressed genes are shown in a heat map in Fig. 2D. For the heat map of this study, the expression of
Bcarl and Lamcl exhibited a high level in ASCs compare with the NSCs. Besides, the expression of $\mathrm{Vcl}$, Col5a3, Collsal, Ezr, Itgb6, Col3al and Stat5a exhibited a low level in ASCs compare with the NSCs.

Analysis of functional categories of differentially methylated genes. The results of GO analysis are shown in Fig. 3A. The differentially methylated genes were significantly enriched in BPs, including 'regulation of biological process' (GO:0050789), 'regulation of cellular process' (GO:0050794), 'biological regulation' (GO:0065007), 'cell adhesion' (GO:0007155) and 'cellular process' (GO:0009987). The enriched CCs included 'cell periphery' (GO:0071944), 'plasma membrane' (GO:0005886), 'cell part' (GO:0044464), 'membrane' (GO:0016020) and 'membrane part' (GO:0044425). The enriched MFs included 'binding' (GO:0005488), 'protein binding' (GO:0005515), 'signaling receptor binding' (GO:0005102), 'ion binding' (GO:0043167) and 'carbohydrate derivative binding' (GO:0097367). 
$\mathbf{A}$

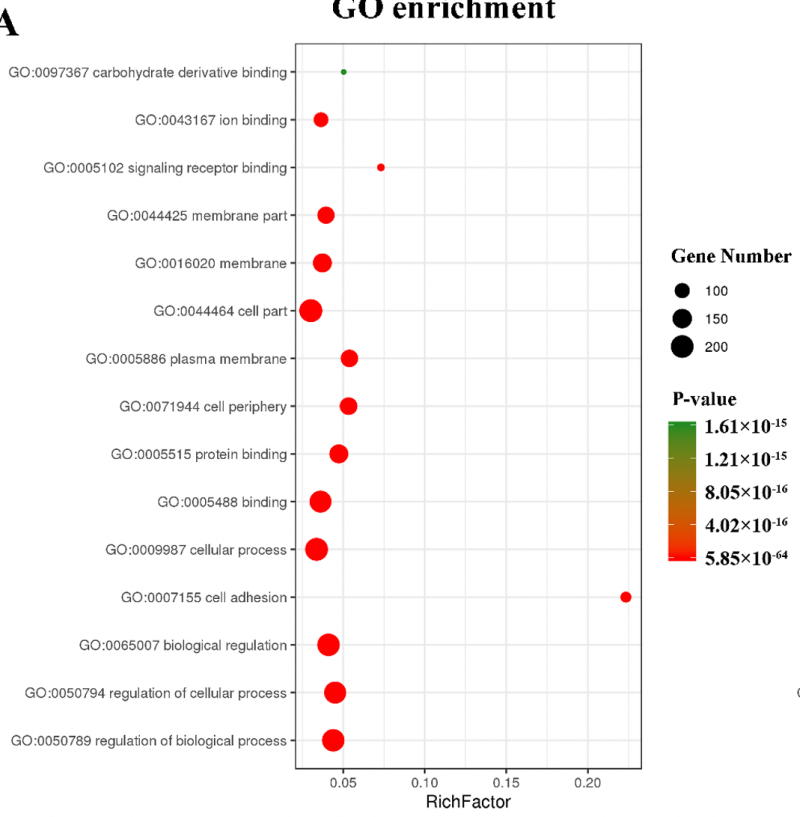

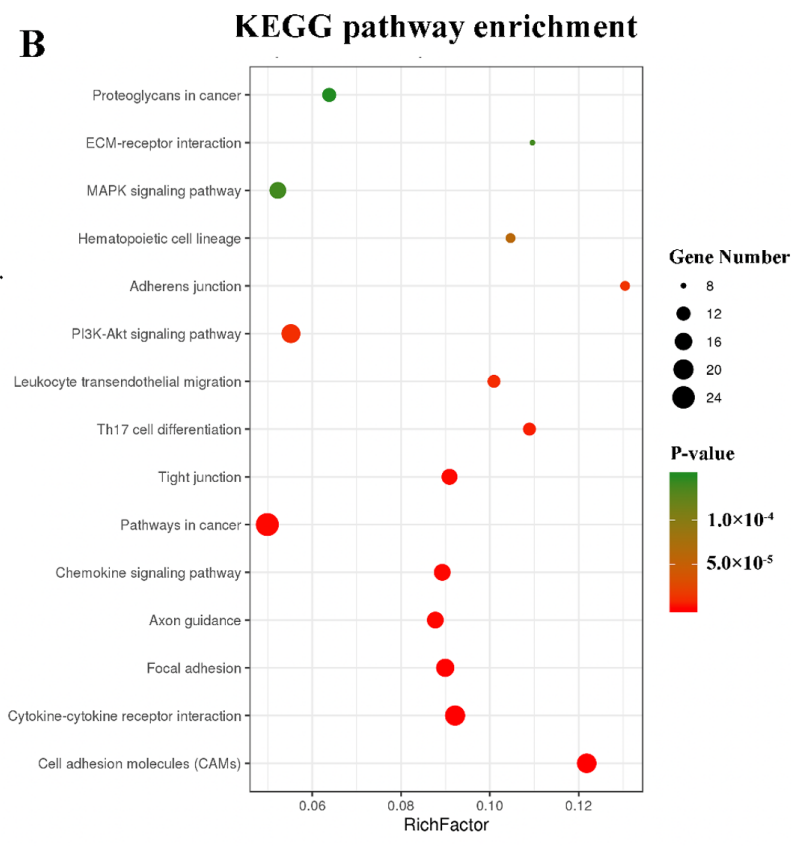

C

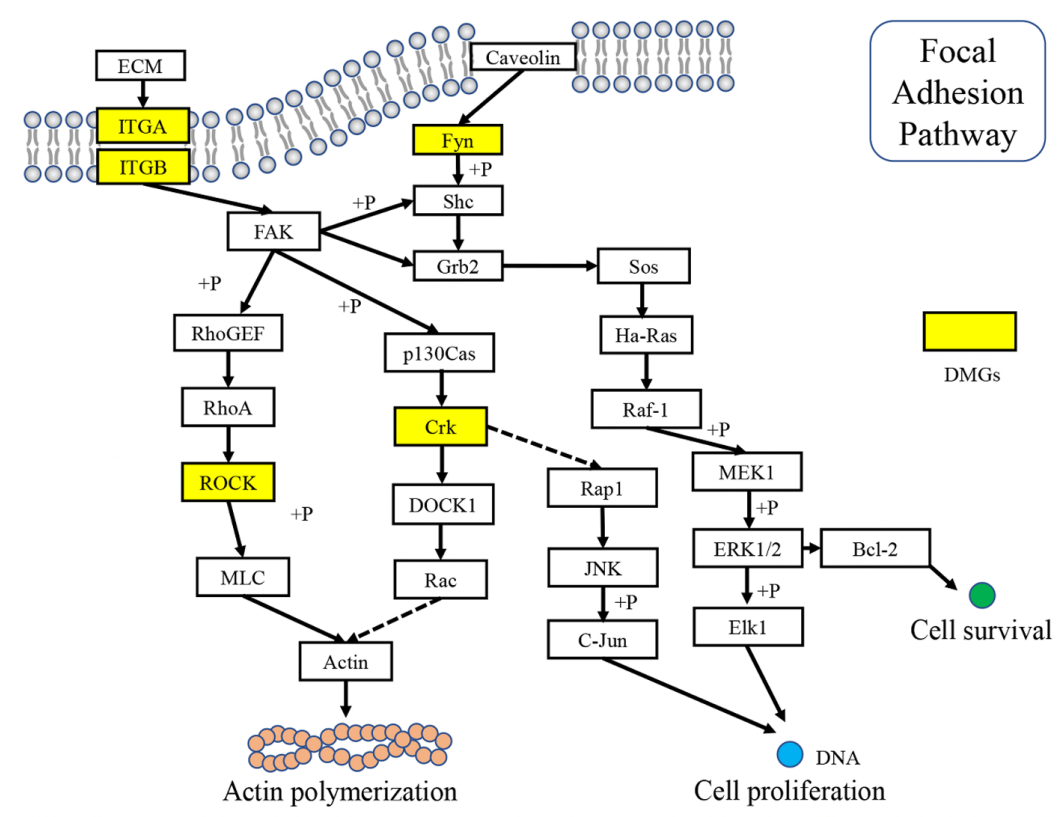

Figure 3. Bioinformatics analysis. (A) GO and (B) KEGG pathway analysis of adhesion-associated differentially expressed genes in schwann cells. (C) ITGA/ITGB, ROCK, Fyn and Crk may be associated with cell proliferation and survival through the focal adhesion pathway. GO, Gene Ontology; KEGG, Kyoto Encyclopedia of Genes and Genomes; DMGs, differentially methylated genes; ECM, extracellular matrix.

KEGG pathway analysis results are shown in Fig. 3B. Of all adhesion-associated differentially methylated genes, the 15 most enriched pathways were selected. According to the KEGG pathway analysis results, differentially methylated genes were significantly enriched in 'Cell adhesion molecules', 'Cytokine-cytokine receptor interaction', 'Focal adhesion', 'Pathways in cancer', 'Axon guidance', 'Chemokine signaling pathway', 'Tight junction', 'Th17 cell differentiation', 'Leukocyte transendothelial migration', 'PI3K-Akt signaling pathway', 'Adherens junction', 'Hematopoietic cell lineage', 'ECM-receptor interaction', 'MAPK signaling pathway' and
'Proteoglycans in cancer'. The differentially methylated genes in ASCs compared with NSCs involved in the 'Focal adhesion' pathway are shown in Fig. 3C.

ITGA/ITGB, ROCK, Fyn and Crk were the differential methylated genes detected in MeDIP-seq, suggesting that these genes may be associated with actin polymerization, cell proliferation and survival through the focal adhesion pathway.

PPI network analysis. PPI network analysis was performed using STRING. The PPI network of differentially methylated 
A

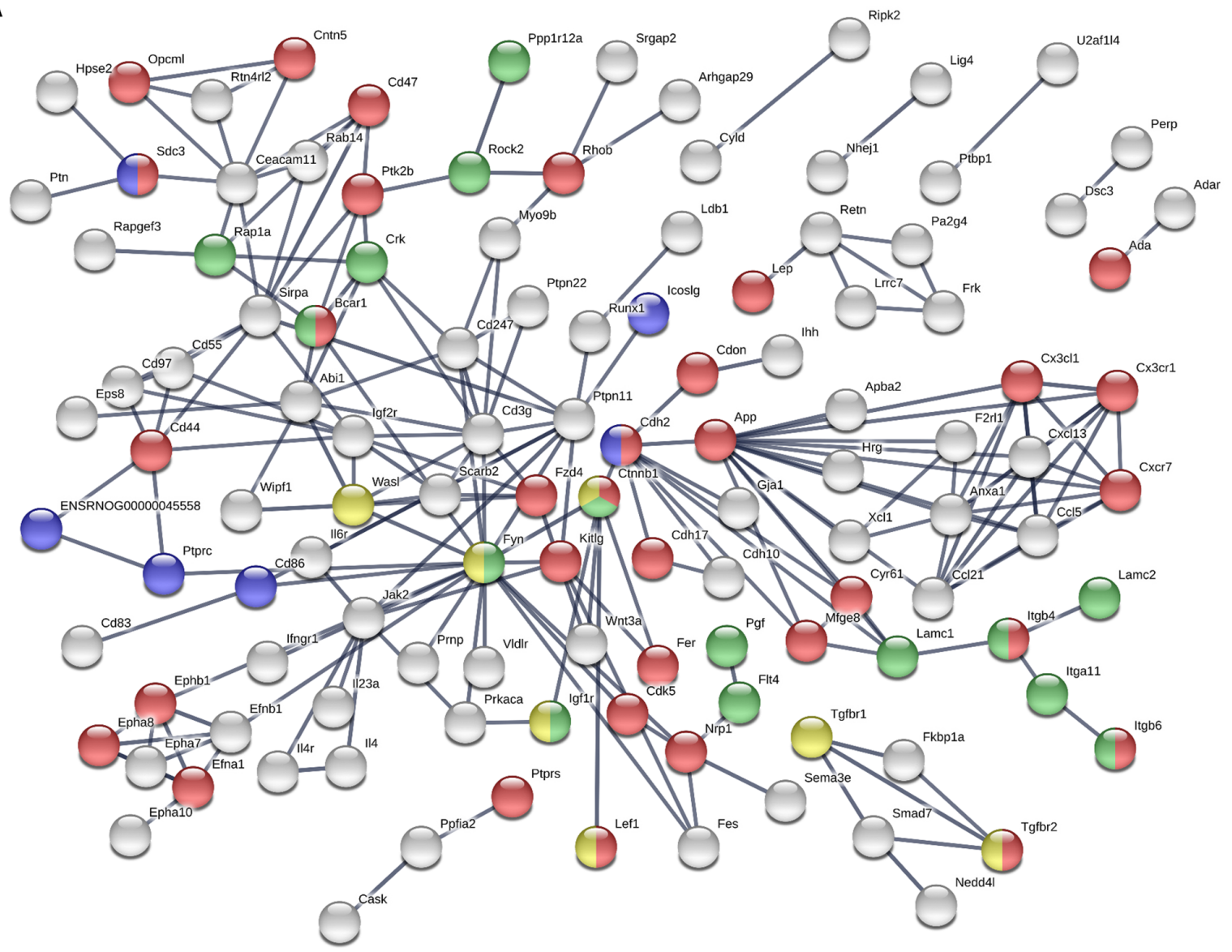

GO:0007155 cell adhesion

Pathway:rno04514 cell adhesion molecules (CAMs)

Pathway:rno04510 focal adhesion

Pathway:rno04520 adherens junction
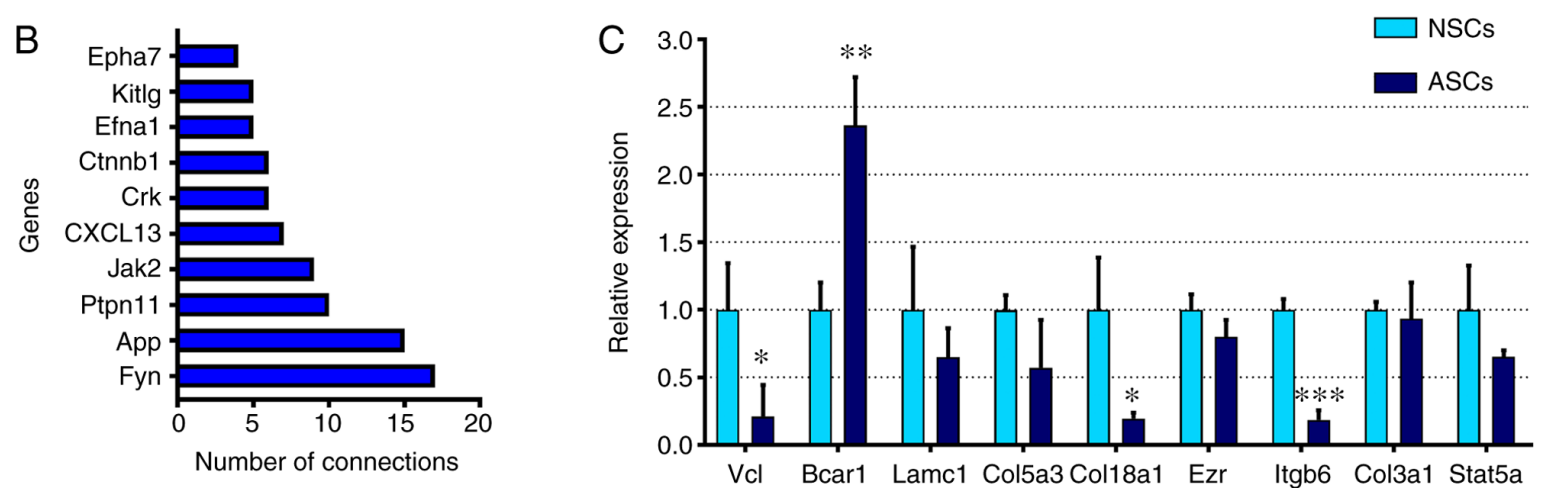

Figure 4. Bioinformatics analysis and verification by RTq-PCR. (A) PPI network analysis of adhesion-associated differentially expressed genes in schwann cells. (B) The top 10 high-degree hub nodes in the PPI network. (C) Expression levels of adhesion-associated genes verified via reverse transcription-quantitative PCR. Values are expressed as the mean \pm SEM. ${ }^{*} \mathrm{P}<0.05 ;{ }^{* * *} \mathrm{P}<0.01 ;{ }^{* * * *} \mathrm{P}<0.001$ vs. NSCs. PPI, protein-protein interaction; NSCs, normal Schwann cells; ASCs, activated Schwann cells; GO, Gene Ontology; Vcl, vinculin; Bcarl, BCAR1 scaffold protein; Lamc1, laminin subunit $\gamma 1$; Col5a3, collagen type V $\alpha 3$ chain; Col18a1, collagen type XVIII $\alpha 1$ chain; Ezr, ezrin; Itgb6, integrin subunit $\beta 6$; Col3a1, collagen type III $\alpha 1$ chain.

genes is shown in Fig. 4A. A total of 294 nodes and 205 interaction pairs were included in the network. Some proteins involved in the 'Focal adhesion' pathway, such as Lamc1, Lamc2, Itga11, Bcar1, Fyn, Rock2, Flt3, Kdr and Pgf, were central nodes in the present network. Some proteins involved in the 'Cell adhesion molecules' pathway, such as Sdc3, Cd276, Ptprc, Cd86, Lcam1 and Alcam, were also central nodes in the network. The top 10 high-degree hub nodes included Fyn,
App, Ptpn11, Jak2, Cxc113, Crk, Ctnnb1, Efna1, Kitlg and Epha7 (Fig. 4B). Among these proteins, Fyn was the node with the highest degree.

Validation of differentially expressed genes via RT-qPCR. To further investigate the changes in cell adhesion, RT-qPCR was performed to explore several known adhesion-associated genes (Vcl, Bcarl, Lamcl, Col5a3, Coll8al, Ezr, Itgb6, Col3al and 
Stat5a) in NSCs and ASCs. Among these genes, Bcarl expression was significantly upregulated, while the expression levels of $\mathrm{Vcl}, \mathrm{Coll} 8 \mathrm{al}$ and Itgb6 were significantly downregulated in ASCs compared with in NSCs (Fig. 4C). The present results indicated that these genes may cause changes in Schwann cell adhesion after PNI.

\section{Discussion}

DNA methylation, histone modification and non-coding RNA regulation have been studied in previous epigenetic research (31,52-54). In our previous studies, genome-wide methylation analyses and iTRAQ-based proteomics profiling of Schwann cells after PNI were performed $(23,35)$. The Schwann cell phenotype induced by DNA methylation is known to change after PNI, but this phenomenon requires further investigation (55-57). In the present study, a unilateral sciatic nerve injury model was established using the proximal region of the sciatic nerve in Wistar rats. A previous study reported differences in the expression of immunomodulatory genes between the proximal and distal segments after PNI (58). Future studies should investigate DNA methylation changes between the proximal and distal segments after PNI. The present study identified and characterized Schwann cells, and revealed that the proliferative and adhesive abilities of ASCs were stronger than those of NSCs. Additionally, MeDIP-seq was used to identify epigenetic changes between NSCs and ASCs. A total of 429 adhesion-associated differentially methylated genes and 15 closely associated signaling pathways were identified. After performing GO, KEGG signaling pathway and PPI network analyses, the genes of heat map were verified by RT-qPCR and were determined to be potential regulators of rat Schwann cell proliferation and adhesion.

The present study investigated epigenetic changes that occurred after nerve injury. Among the adhesion-associated differentially methylated genes identified in the present study, several important genes have been implicated in cell adhesion or proliferation, including Bcarl, Col5a3, Coll8al, Ezr, Col3al and Stat5a (59-61).

Notably, Bcarl was one of the differentially methylated genes identified in the present study. Bcarl is a vital scaffolding protein that modulates numerous essential cellular processes $(62,63)$. It belongs to the Crk-associated substrate family of scaffolding proteins (64). There is increasing evidence that Bcarl serves a crucial role in cell-extracellular matrix adhesion, tissue homeostasis and pathogenesis of Kaposi's sarcoma-associated herpesvirus (65). Furthermore, the lack of Bcarl in some cells may lead to altered integrin signaling, which is reflected by aberrant basal membrane adhesion (63). This is consistent with the expression of changes in core genes that affect adhesion in Schwann cells after PNI, as shown in the present study.

In the KEGG analysis in the current study, the differentially methylated genes were significantly enriched in several pathways, including 'cell adhesion molecules', 'cytokine-cytokine receptor interaction' and 'focal adhesion' pathways. It has been reported that the focal adhesion pathway is regulated by microRNA (miR)-29s, while the Lamcl gene is a candidate target of miR-29s regulation (66). This indicates that Lamcl may regulate the focal adhesion pathway indirectly through miR-29s. Additionally, a previous study demonstrated that the presence of Lamcl may promote the migration without affecting the proliferative activity of prostate cancer cells (66). After PPI network analysis of the differentially methylated genes, the top 10 high-degree hub nodes included Fyn, Efna1, Jak2, Vav3, Flt4, Epha7, Crk, Kitlg, Ctnnb1 and Ptpn11.

Although the current study revealed numerous epigenetic changes after PNI in Wistar rats, some limitations were noted. First, even though it has been reported that rats are useful animal models for experimental studies of peripheral neuropathology and repair, future experiments should focus on large animals and primate models $(67,68)$. Second, the present study used unilateral ligation of one sciatic nerve, while the other nerve served as the control. However, it is unclear whether unilateral ligation of one sciatic nerve may affect the other nerve. A previous study reported that the recoveries observed using an upper limb model were faster, and the time required for function restoration was shorter, compared with the model of sciatic nerve injury (69). Additionally, the sciatic nerve cannot represent all the peripheral nerves. Third, it should be noted that the current study only examined the adhesion and proliferation of Schwann cells. Schwann cells have numerous additional functions that occur before and after PNI, including cell migration, cell secretion and axonal regeneration, which require further research.

In conclusion, the present results provided novel information concerning basic Schwann cell adhesion. However, in vitro culture, amplification and purification of Schwann cells are complex processes. It is challenging to obtain Schwann cells in sufficient numbers, with substantial purity and biological activity, no immune rejection and limited proliferation characteristics (70). Proliferation, adhesion and migration may markedly change with the epigenetic changes that occur in ASCs. Therefore, Schwann cell transplantation in peripheral nerve repair requires to overcome numerous difficulties (71). The present study performed bioinformatics analyses of DNA methylation patterns associated with Schwann cell adhesion and proliferation. A total of 429 differentially methylated genes were identified in ASCs compared with in NSCs. Among these genes, Vcl, Bcarl, Coll8al and Itgb6 may affect cell adhesion after PNI. The screened genes and pathways suggested potential candidates for further study of epigenetic mechanisms associated with Schwann cells.

\section{Acknowledgements}

Not applicable.

\section{Funding}

The present study was supported by grants from the State Key Program of National Natural Science Foundation of China (grant no. 81930070), the State General Program National Natural Science Foundation of China (grant no. 81371957), the International Cooperation Program of National Natural Science Foundation of China (grant no. 81620108018), the Key Program Sponsored by the Tianjin Science and Technology Committee of China (grant nos. 14ZCZDSY00044 and13RCGFSY19000),KeyProjectsforScienceandTechnology Support (the Tianjin Key Research and Development Plan, grant no. 19YFZCSY0060), China Scholarship Council and 
Tianjin Research Innovation Project for Postgraduate Students (grant no. 2019YJSB109), and Postgraduate Innovation Fund of '13th Five-Year comprehensive investment' of Tianjin Medical University. (grant no. YJSCX201903).

\section{Availability of data and materials}

For all datasets from (STRING) database (a publicly available database; http://string-db.org/), data are available from the authors upon reasonable request and with permission of STRING. The other datasets used and/or analyzed during the current study are available from the corresponding author on reasonable request.

\section{Authors' contributions}

SZ, GS and JF designed the study. GS analyzed the data and wrote the manuscript. XZha, BF, SL, YH and ZW collected and analyzed all data. XZho and SF acquired funding, made substantial contributions to the study design and gave final approval of the version to be published. All authors read and approved the final manuscript. All the above authors critically revised the manuscript for important intellectual content and made substantial contributions to conception and design.

\section{Ethics approval and consent to participate}

All animal procedures were approved by the Animal Ethics Committee of Tianjin Medical University General Hospital (Tianjin, China) in January 2019 (approval no.IRB2019-WZ-004). All experimental procedures described were in accordance with the Guide for the Care and Use of Laboratory Animals (38).

\section{Patient consent for publication}

Not applicable.

\section{Competing interests}

The authors declare that they have no competing interests.

\section{References}

1. Ghosh M,Tuesta LM,Puentes R,Patel S, Melendez K,El Maarouf A, Rutishauser U and Pearse DD: Extensive cell migration, axon regeneration, and improved function with polysialic acid-modified Schwann cells after spinal cord injury. Glia 60: 979-992, 2012.

2. Parrinello S, Napoli I, Ribeiro S, Wingfield Digby P, Fedorova M, Parkinson DB, Doddrell RD, Nakayama M, Adams RH and Lloyd AC: EphB signaling directs peripheral nerve regeneration through Sox2-dependent Schwann cell sorting. Cell 143: 145-155, 2010.

3. Stassart RM, Fledrich R, Velanac V, Brinkmann BG, Schwab MH, Meijer D, Sereda MW and Nave KA: A role for Schwann cell-derived neuregulin-1 in remyelination. Nat Neurosci 16: 48-54, 2013.

4. Scheib J and Höke A: Advances in peripheral nerve regeneration. Nat Rev Neuro 9: 668-676, 2013.

5. Johnson S, Ayling H, Sharma M and Goebel A: External noninvasive peripheral nerve stimulation treatment of neuropathic pain: A prospective audit. Neuromodulation 18: 384-391, 2015.

6. Jessen KR and Mirsky R: The success and failure of the schwann cell response to nerve injury. Front Cell Neurosci 13: 33, 2019.

7. Pereira JA, Lebrun-Julien F and Suter U: Molecular mechanisms regulating myelination in the peripheral nervous system. Trends Neurosci 35: 123-134, 2012.
8. Esposito E and Cuzzocrea S: Anti-TNF therapy in the injured spinal cord. Trends Pharmacol Sci 32: 107-115, 2011.

9. Zhang H, Shao Z, Zhu Y, Shi L, Li Z, Hou R, Zhang C and Yao D: Toll-like receptor 4 (TLR4) expression affects Schwann cell behavior in vitro. Sci Rep 8: 11179, 2018.

10. Zhu H, Xue C, Yao M, Wang H, Zhang P, Qian T, Zhou S, Li S, $\mathrm{Yu} \mathrm{B}$, Wang Y and Gu X: miR-129 controls axonal regeneration via regulating insulin-like growth factor-1 in peripheral nerve injury. Cell Death Dis 9: 720, 2018.

11. Staser K, Yang FC and Clapp DW: Mast cells and the neurofibroma microenvironment. Blood 116: 157-164, 2010.

12. Painter MW, Brosius Lutz A, Cheng YC, Latremoliere A, Duong K, Miller CM, Posada S, Cobos EJ, Zhang AX, Wagers AJ, et al: Diminished Schwann cell repair responses underlie age-associated impaired axonal regeneration. Neuron 83: 331-343, 2014

13. Lopez-Verrilli MA, Picou F and Court FA: Schwann cell-derived exosomes enhance axonal regeneration in the peripheral nervous system. Glia 61: 1795-1806, 2013.

14. Li A, Hokugo A, Yalom A, Berns EJ, Stephanopoulos N, McClendon MT, Segovia LA, Spigelman I, Stupp SI and Jarrahy R: A bioengineered peripheral nerve construct using aligned peptide amphiphile nanofibers. Biomaterials 35 : 8780-8790, 2014.

15. Afshari FT, Kwok JC, White L and Fawcett JW: Schwann cell migration is integrin-dependent and inhibited by astrocyte-produced aggrecan. Glia 58: 857-869, 2010.

16. Huang H, Mao G, Chen L and Liu A: Progress and challenges with clinical cell therapy in neurorestoratology. J Neurorestoratol 3: 91-95, 2015.

17. Campana WM: Schwann cells: Activated peripheral glia and their role in neuropathic pain. Brain Behav Immun 21: 522-527, 2007.

18. Guertin AD, Zhang DP, Mak KS, Alberta JA and Kim HA: Microanatomy of axon/glial signaling during Wallerian degeneration. J Neurosci 25: 3478-3487, 2005.

19. Weis J, Claeys KG, Roos A, Azzedine H, Katona I, Schröder JM and Senderek J: Towards a functional pathology of hereditary neuropathies. Acta Neuropathol 133: 493-515, 2017.

20. Boilly B, Faulkner S, Jobling P and Hondermarck H: Nerve dependence: From regeneration to cancer. Cancer Cell 31: 342-354, 2017.

21. Akassoglou K, Yu WM, Akpinar P and Strickland S: Fibrin inhibits peripheral nerve remyelination by regulating Schwann cell differentiation. Neuron 33: 861-875, 2002.

22. Keilhoff G, Fansa H, Schneider W and Wolf G: In vivo predegeneration of peripheral nerves: An effective technique to obtain activated Schwann cells for nerve conduits. J Neurosci Methods 89: 17-24, 1999.

23. Shi GD, Zhang XL, Cheng X, Wang X, Fan BY, Liu S, Hao Y, Wei ZJ, Zhou XH and Feng SQ: Abnormal DNA methylation in thoracic spinal cord tissue following transection injury. Med Sci Monit 24: 8878-8890, 2018.

24. Zhou XH, Ning GZ, Feng SQ, Kong XH, Chen JT, Zheng YF, Ban DX, Liu T, Li H and Wang P: Transplantation of autologous activated Schwann cells in the treatment of spinal cord injury: Six cases, more than five years of follow-up. Cell Transplantat 21 (Suppl 1): S39-S47, 2012.

25. Zhou X, Shi G, Fan B, Cheng X, Zhang X, Wang X, Liu S, Hao Y, Wei Z, Wang L and Feng S: Polycaprolactone electrospun fiber scaffold loaded with iPSCs-NSCs and ASCs as a novel tissue engineering scaffold for the treatment of spinal cord injury. Int J Nanomedicine 13: 6265-6277, 2018.

26. Ma T, Zhu L, Yang Y, Quan X, Huang L, Liu Z, Sun Z, Zhu S, Huang $J$ and Luo Z: Enhanced in vivo survival of Schwann cells by a synthetic oxygen carrier promotes sciatic nerve regeneration and functional recovery. J Tissue Eng Regen Med 12: e177-e189, 2016.

27. Bender J: DNA methylation and epigenetics. Annu Rev Plant Biol 55: 41-68, 2004.

28. Lev Maor G, Yearim A and Ast G: The alternative role of DNA methylation in splicing regulation. Trends Genet 31: 274-280, 2015.

29. FilipponiD,Muller J,Emelyanov A and Bulavin DV: Wip1 controls global heterochromatin silencing via ATM/BRCA1-dependent DNA methylation. Cancer Cell 24: 528-541, 2013.

30. Garriga J, Laumet G, Chen SR, Zhang Y, Madzo J, Issa JJ, Pan HL and Jelinek J: Nerve injury-induced chronic pain is associated with persistent DNA methylation reprogramming in dorsal root ganglion. J Neurosci 38: 6090-6101, 2018. 
31. Shi G,Zhou X, Wang X,Zhang X,Zhang P and Feng S: Signatures of altered DNA methylation gene expression after central and peripheral nerve injury. J Cell Physiol 235: 5171-5181, 2020.

32. Finnegan EJ, Genger RK, Peacock WJ and Dennis ES: DNA METHYLATION IN PLANTS. Annu Rev Plant Physiol Plant Mol Biol 49: 223-247, 1998.

33. Gölzenleuchter M, Kanwar R, Zaibak M, Al Saiegh F, Hartung T, Klukas J, Smalley RL, Cunningham JM, Figueroa ME, Schroth GP, et al: Plasticity of DNA methylation in a nerve injury model of pain. Epigenetics 10: 200-212, 2015.

34. Zhou XH, Lin W, Ren YM, Liu S, Fan BY, Wei ZJ, Shi GD, Cheng X, Hao Y and Feng SQ: Comparison of DNA methylation in schwann cells before and after peripheral nerve injury in rats. Biomed Res Int 2017: 5393268, 2017.

35. Shi GD, Cheng X, Zhou XH, Fan BY, Ren YM, Lin W, Zhang XL, Liu S, Hao Y, Wei ZJ and Feng SQ: iTRAQ-based proteomics profiling of Schwann cells before and after peripheral nerve injury. Iran J Basic Med Sci 21: 832-841, 2018.

36. Bennett GJ and Xie YK: A peripheral mononeuropathy in rat that produces disorders of pain sensation like those seen in man. Pain 33: 87-107, 1988.

37. Michot B, Deumens R and Hermans E: Immunohistochemical comparison of astrocytic mGluR5 upregulation in infraorbital nerve-versus sciatic nerve-ligated rat. Neurosci Lett 653: 113-119, 2017.

38. National Research Council Committee for the Update of the Guide for the $\mathrm{C}$ and Use of Laboratory A: The National Academies Collection: Reports funded by National Institutes of Health. In: Guide for the Care and Use of Laboratory Animals National Academies Press (US) Copyright ${ }^{\mathcal{O}}$ 2011, National Academy of Sciences., Washington (DC), 2011.

39. Chisholm JM and Pang DS: Assessment of carbon dioxide, carbon dioxide/oxygen, isoflurane and pentobarbital killing methods in adult female Sprague-Dawley rats. PLoS One 11: e0162639, 2016.

40. Hickman DL and Johnson SW: Evaluation of the aesthetics of physical methods of euthanasia of anesthetized rats. J Am Assoc Lab Anim Sci 50: 695-701, 2011

41. Stutler SA, Johnson EW, Still KR, Schaeffer DJ, Hess RA and Arfsten DP: Effect of method of euthanasia on sperm motility of mature Sprague-Dawley rats. J Am Assoc Lab Anim Sci 46: 13-20, 2007.

42. Yang $M$ and Zhou $\mathrm{H}$ : Grass carp transforming growth factor-beta 1 (TGF-beta 1): Molecular cloning, tissue distribution and immunobiological activity in teleost peripheral blood lymphocytes. Mol Immunol 45: 1792-1798, 2008.

43. Zhao H, Zhang Y, Sun J, Zhan C and Zhao L: Raltitrexed inhibits HepG2 cell proliferation via G0/G1 cell cycle arrest. Oncol Res 23: 237-248, 2016.

44. Wang X, Niu Z, Jia Y, Cui M, Han L, Zhang Y, Liu Z, Bi D and Liu S: Ubenimex inhibits cell proliferation, migration and invasion by inhibiting the expression of APN and inducing autophagic cell death in prostate cancer cells. Oncol Rep 35: 2121-2130, 2016.

45. Xiao G, Cheng H, Cao H, Chen K, Tu Y, Yu S, Jiao H, Yang S, Im HJ, Chen D, et al: Critical role of filamin-binding LIM protein 1 (FBLP-1)/migfilin in regulation of bone remodeling. J Biol Chem 287: 21450-21460, 2012.

46. Liu D, Zhang Y, Li X, Li J, Yang S, Xing X, Fan G, Yokota H and Zhang P: eIF2 $\alpha$ signaling regulates ischemic osteonecrosis through endoplasmic reticulum stress. Sci Rep 7: 5062, 2017.

47. Liu Q, Zhu Y, Qi J, Amadio PC, Moran SL, Gingery A and Zhao C: Isolation and characterization of turkey bone marrow-derived mesenchymal stem cells. J Orthop Res 37: 1419-1428, 2019.

48. Livak KJ and Schmittgen TD: Analysis of relative gene expression data using real-time quantitative PCR and the 2(-Delta Delta C(T)) method. Methods 25: 402-408, 2001

49. Li N, Ye M,Li Y, Yan Z, Butcher LM, Sun J, Han X, Chen Q, Zhang X and Wang J: Whole genome DNA methylation analysis based on high throughput sequencing technology. Methods 52: 203-212, 2010

50. Huang da W, Sherman BT, Stephens R, Baseler MW, Lane HC and Lempicki RA: DAVID gene ID conversion tool Bioinformation 2: 428-430, 2008.

51. Szklarczyk D, Franceschini A, Wyder S, Forslund K, Heller D, Huerta-Cepas J, Simonovic M, Roth A, Santos A, Tsafou KP, et al: STRING v10: Protein-protein interaction networks, integrated over the tree of life. Nucleic Acids Res 43: D447-D452, 2015.

52. Petersen SC, Luo R, Liebscher I, Giera S, Jeong SJ, Mogha A, Ghidinelli M, Feltri ML, Schöneberg T, Piao X and Monk KR: The adhesion GPCR GPR126 has distinct, domain-dependent functions in Schwann cell development mediated by interaction with laminin-211. Neuron 85: 755-769, 2015.
53. Jessen KR and Arthur-Farraj P: Repair Schwann cell update: Adaptive reprogramming, EMT, and stemness in regenerating nerves. Glia 67: 421-437, 2019

54. Zhao X, Chen C, Wei Y, Zhao G, Liu L, Wang C, Zhang J and Kong X: Novel mutations of COL4A3, COL4A4, and COL4A5 genes in Chinese patients with Alport Syndrome using next generation sequence technique. Mol Genet Genomic Med 7: e653, 2019.

55. Assinck P, Duncan GJ, Hilton BJ, Plemel JR and Tetzlaff W: Cell transplantation therapy for spinal cord injury. Nat Neurosci 20 637-647, 2017.

56. Li L, Xiong WC and Mei L: Neuromuscular junction formation, aging, and disorders. Annu Rev Physiol 80: 159-188, 2018.

57. Adams D, Koike H, Slama M and Coelho T: Hereditary transthyretin amyloidosis: A model of medical progress for a fatal disease. Nat Rev Neurol 15: 387-404, 2019

58. Chernov AV, Dolkas J, Hoang K, Angert M, Srikrishna G, Vog1 T, Baranovskaya S, Strongin AY and Shubayev VI: The calcium-binding proteins S100A8 and S100A9 initiate the early inflammatory program in injured peripheral nerves. J Biol Chem 290: 11771-11784, 2015.

59. Ratushnyy AY and Buravkova LB: Expression of focal adhesion genes in mesenchymal stem cells under simulated microgravity. Dokl Biochem Biophys 477: 354-356, 2017.

60. Chen Y, Teng L, Liu W, Cao Y, Ding D, Wang W, Chen H, Li C and An R: Identification of biological targets of therapeutic intervention for clear cell renal cell carcinoma based on bioinformatics approach. Cancer Cell Int 16: 16, 2016.

61. Tabur S, Oztuzcu S, Oguz E, Demiryürek S, Dagli H, Alasehirli B, Ozkaya $\mathrm{M}$ and Demiryürek AT: Evidence for elevated (LIMK2 and CFL1) and suppressed (ICAM1, EZR, MAP2K2, and NOS3) gene expressions in metabolic syndrome. Endocrine 53: 465-470, 2016.

62. Fromont $\mathrm{G}$, Vallancien $\mathrm{G}$, Validire $\mathrm{P}$, Levillain $\mathrm{P}$ and Cussenot $\mathrm{O}$ BCAR1 expression in prostate cancer: Association with 16q23 LOH status, tumor progression and EGFR/KAI1 staining. Prostate 67: 268-273, 2007.

63. Camacho Leal MD, Costamagna A, Tassone B, Saoncella S, Simoni M, Natalini D, Dadone A, Sciortino M, Turco E, Defilippi P, et al: Conditional ablation of p130Cas/BCAR1 adaptor protein impairs epidermal homeostasis by altering cell adhesion and differentiation. Cell Commun Signal 16: 73, 2018.

64. Camacho Leal Mdel P, Sciortino M, Tornillo G, Colombo S, Defilippi P and Cabodi S: p130Cas/BCAR1 scaffold protein in tissue homeostasis and pathogenesis. Gene 562: 1-7, 2015.

65. Barrett A, Pellet-Many C, Zachary IC, Evans IM and Frankel P: p130Cas: A key signalling node in health and disease. Cell Signal 25: 766-777, 2013.

66. Nishikawa R, Goto Y, Kojima S, Enokida H, Chiyomaru T, Kinoshita T, Sakamoto S, Fuse M, Nakagawa M, Naya Y, et al: Tumor-suppressive microRNA-29s inhibit cancer cell migration and invasion via targeting LAMC1 in prostate cancer. Int J Oncol 45: 401-410, 2014.

67. Zhang P, Kou Y, Yin X, Wang Y, Zhang H and Jiang B: The experimental research of nerve fibers compensation amplification innervation of ulnar nerve and musculocutaneous nerve in rhesus monkeys. Artif Cells Blood Substit Immobil Biotechnol 39: 39-43, 2011.

68. Hu J, Zhu QT, Liu XL, Xu YB and Zhu JK: Repair of extended peripheral nerve lesions in rhesus monkeys using acellular allogenic nerve grafts implanted with autologous mesenchymal stem cells. Exp Neurol 204: 658-666, 2007.

69. Bontioti EN, Kanje M and Dahlin LB: Regeneration and functional recovery in the upper extremity of rats after various types of nerve injuries. J Peripher Nerv Syst 8: 159-168, 2003.

70. Zhu J, Qin J, Shen Z, Kretlow JD, Wang X, Liu Z and Jin Y: Dispase rapidly and effectively purifies Schwann cells from newborn mice and adult rats. Neural Regen Res 7: 256-260, 2012.

71. Wang G, Ma Z, Cao L, Yan G, Wang Y, Jin Y, Shen H, Zhang Y, $\mathrm{Xu} X$, Chen X and Shen Z: A novel method for obtaining highly enriched Schwann cell populations from mature monkey nerves based on in vitro pre-degeneration. Mol Med Rep 16: 6600-6607, 2017.

This work is licensed under a Creative Commons Attribution-NonCommercial-NoDerivatives 4.0 International (CC BY-NC-ND 4.0) License. 